\title{
Investigations into Wear and Galling Mechanism of Aluminium Alloy-Tool Steel Tribopair at Different Temperatures
}

\author{
JPujante $^{1 *}$ L Pelcastre $^{2}$, M Vilaseca $^{1}$, D Casellas $^{1,3}$, B Prakash $^{2}$ \\ ${ }^{1}$ Fundació CTM Centre Tecnològic, Avda. Bases de Manresa, 1, 08242 Manresa, Spain. \\ ${ }^{2}$ Department of Engineering Sciences and Mathematics, Division of Machine Elements, Luleå University of Technology, \\ SE-971 87 Luleå, Sweden \\ ${ }^{3}$ Department of Materials Science and Metallurgical Engineering, Universitat Politècnica de Catalunya, Avda. Bases de \\ Manresa 61, 08242 Manresa, Spain.
}

\begin{abstract}
Aluminium alloys show poor formability at room temperature, and the production of complex components requires a series of high temperature forming processes, such as warm and hot forging, extrusion and hot sheet metal forming. Forming aluminium in these conditions subjects the tools to severe adhesive wear and galling, leading to increased energy needs, shorter tool life, lower part quality and increased cost. In this work, the wear mechanisms generated by aluminium alloys on forming tools have been studied by means of linear reciprocating sliding tests. Aluminium alloy AA2017 balls were slid against DIN 1.2344 (AISI H13) tool steel samples with various surface finishes at temperatures up to $450{ }^{\circ} \mathrm{C}$. The main results show that the observed wear mechanisms are extremely dependent on the system temperature, ranging from pure abrasive wear to formation of layers of compacted aluminium debris and gross aluminium transfer in the form of lumps. On the other hand, tool surface finish has a limited effect on gross material transfer, but does affect the material transfer micromechanisms.
\end{abstract}

Keywords: Wear, Galling, Metal Forming, Aluminium, High Temperature

*Corresponding author: Jaume Pujante (jaume.pujante@ctm.com.es).

\section{INTRODUCTION}

Aluminium-based alloys present a number of interesting properties, such as low density, corrosion resistance, thermal and electrical conductivity and good recyclability. In addition, high mechanical properties can be obtained through precipitation hardening, allowing their application in structural components. For all these reasons, there is a strong trend in increasing the use of aluminium, particularly in the automotive industry [1]. However, aluminium alloys show poor formability at room temperature, and the production of complex components requires a series of forming processes, such as warm and hot forging, extrusion and hot sheet metal forming [2], which involve heating the component at temperatures ranging from $150{ }^{\circ} \mathrm{C}$ to more than $500{ }^{\circ} \mathrm{C}$. Forming aluminium in these conditions subjects the tools to severe adhesive wear and galling, leading to increased energy needs, shorter tool life, lower part quality and increased cost.
Galling in aluminium forming is known to occur at temperatures even lower than $100{ }^{\circ} \mathrm{C}$ [3], locally achieved by frictional heating in processes such as deep drawing. Systematic studies at room temperature of aluminium sliding on tool steel have been performed by authors such as Heinrichs et al [4], who studied galling and the role of surface defects as adhesion initiation sites through crossed-cylinder tests.

However, the investigation of wear mechanisms at high temperature presents added complexity, due to factors such as oxidation, material softening and chemical and metallurgical interactions. There is limited research on how system temperature can affect the overall tribological behaviour. Instead, existing high temperature studies are mostly restricted to reproducing a particular wear mechanism in an industrial process, such as the works of Pellizzari [5] or Wang [6], who investigated galling in aluminium extrusion at temperatures up to $500{ }^{\circ} \mathrm{C}$ through different experimental setups, or Vilaseca et al [7], who designed a test for evaluating the resistance to aluminium adhesion of HPDC tool steels and coatings. 
The aim of this work is to study the relevance of temperature and tool steel surface finish on the occurrence of galling, and to determine the temperature range at which various wear mechanisms take place in the aluminium-tool steel system. This has been accomplished through a series of linear reciprocating ball-on-disc sliding tests, using aluminium alloy AA2017 balls on DIN 1.2344 tool steel disc samples at temperatures between $30^{\circ} \mathrm{C}$ and $450{ }^{\circ} \mathrm{C}$.

\section{METHODOLOGY}

\subsection{Materials}

Disk samples $24 \mathrm{~mm}$ in diameter and $7.8 \mathrm{~mm}$ thick were obtained from DIN 1.2344 tool steel (AISI H 13), a standard tool steel widely used in many hot work applications, heat treated to $53 \pm 1 \mathrm{HRC}$. Three sets of samples were prepared with different surface finishes. One first set was ground and polished to an average $\mathrm{Ra}$ roughness under $0.1 \mu \mathrm{m}$. A second set was unidirectionally ground in grit $60 \mathrm{SiC}$ paper, obtaining a pattern of parallel grinding lines with $\mathrm{Ra} 0.4 \mu \mathrm{m}$. A third set was "eight-ground" in grit $60 \mathrm{SiC}$ paper, obtaining no preferred orientation and a roughness $\mathrm{Ra}$ of $0.35 \mu \mathrm{m}$.

Aluminium alloy AA2017 balls, $9.5 \mathrm{~mm}$ in diameter and with hardness of $167 \pm 3 \mathrm{HV} 1$ measured at room temperature, were used as friction counterpart,

\subsection{Test equipment and procedure}

Tests were performed on an Optimol SRV high temperature reciprocating friction and wear test machine. In this equipment, the upper specimen (aluminium ball) is mounted in a holder attached to an oscillating electro-mechanical drive, which is pressed against a stationary lower specimen (tool steel disc) mounted on a heating block. Computerized control ensures that normal load is kept constant along the test, and Coefficient of Friction (COF) is measured online. Load, amplitude and frequency conditions were chosen for optimal test stability. The main test parameters are summarized in Table 2. All samples were ultrasonically cleaned in industrial petrol for 3 minutes and rinsed with acetone immediately before testing.

Table 2: Test parameters used with the Optimol SRV equipment.

\begin{tabular}{|c|c|}
\hline Load [N] & 20 \\
\hline Frequency [Hz] & 25 \\
\hline Stroke [mm] & 2 \\
\hline Temperature $\left[{ }^{\circ} \mathbf{C}\right]$ & $30,150,250,350,450$ \\
\hline Test duration $[\mathbf{s}]$ & 10,300 \\
\hline
\end{tabular}

Two sets of tests were performed in this work. In the first set, the different wear mechanisms taking place at the temperature range of aluminium warm and hot forming were studied, using polished tool steel samples at various temperature levels between $30^{\circ} \mathrm{C}$ and $450^{\circ} \mathrm{C}$. Two test durations were chosen: $10 \mathrm{~s}$, corresponding to 250 sliding cycles, and $300 \mathrm{~s}$, corresponding to 7500 cycles, in order to study the onset of wear mechanisms and their full development.

In the second set of tests, the effect of surface finish was analysed through $10 \mathrm{~s}$ tests at $150^{\circ} \mathrm{C}$, using tool steel samples ground in grit $60 \mathrm{SiC}$ paper at different orientations towards the sliding direction.

\subsection{Wear track analysis}

Wear tracks on tool steel samples were inspected by means of electron microscopy and backscattered electron imaging (SEM/BSE), using a Jeol JSM-6460 LV microscope. Low magnification (40x) images were used to observe the wear track morphology and identify transferred material. Higher magnification images (400x and 1000x) gave additional information on the wear micromechanisms. Additional studies were carried out by means of confocal microscopy, using a Sensofar Pl $\mu 2300$ equipment. With this technique it was possible to study the topography of wear tracks, measuring the depth of grooves and the thickness of adhered material.

For the $300 \mathrm{~s}$ tests, ball mass loss was calculated from the wear scars in ball samples studied by means of $25 x$ lens imaging (Fig. 1 a), assimilating ball volume loss to the corresponding spherical cap (Eq. 1).
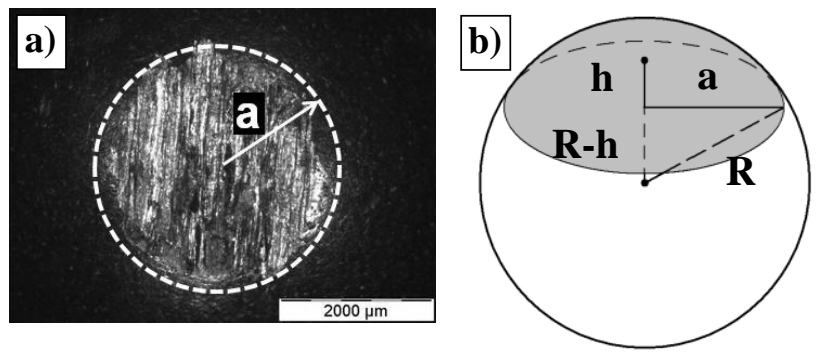

Figure 1: Ball worn volume calculation. a) 25x lens image of a wear scar on a ball sample. b) Spherical cap (grey) corresponding to a wear scar with radius $a$.

$$
\begin{aligned}
& M_{\text {LOSS }} \approx \rho V_{C A P}=\rho \frac{1}{3} \pi h^{2}(3 R-h) \\
& R^{2}=a^{2}+(R-h)^{2}
\end{aligned}
$$

Where $\rho$ is the density of the ball material, $a$ is the radius of the wear scar, $h$ is the height of the spherical cap and $R$ is the ball radius, as defined in Figure $\mathbf{1}$ b. 


\section{RESULTS AND DISCUSSION}

\subsection{Effect of temperature in $10 \mathrm{~s}$ tests}

Tests using polished 1.2344 samples were run for $10 \mathrm{~s}$ at room temperature, $150{ }^{\circ} \mathrm{C}, 250^{\circ} \mathrm{C}, 350^{\circ} \mathrm{C}$ and $450{ }^{\circ} \mathrm{C}$.

Wear tracks corresponding to 10 s tests run at $150^{\circ} \mathrm{C}$ (Fig 2 a), $30^{\circ} \mathrm{C}$ and $250^{\circ} \mathrm{C}$ (not shown) present similar aspect and wear mechanisms. Abrasive grooves approximately $2-3 \mu \mathrm{m}$ deep could be observed in these wear tracks. Material transfer appeared in the form of lumps up to $30 \mu \mathrm{m}$ in thickness, generated when a metallurgical junction formed between the aluminium ball and steel sample and was later sheared during sliding. Additionally, smaller adhesion features, mainly patches of smeared aluminium, can be identified on the tool surface (Fig. 2 b).
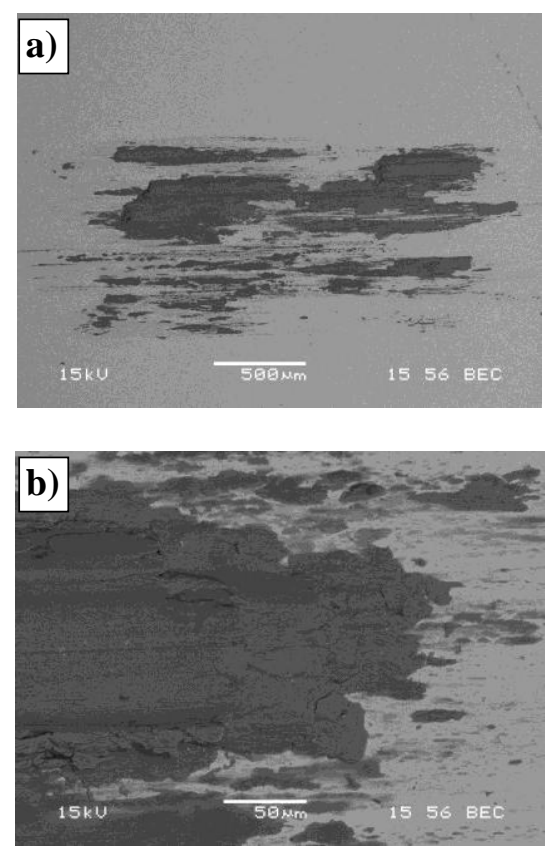

Figure 2: a) SEM/BSE overview of a wear track generated after $10 \mathrm{~s}$ of sliding at $150^{\circ} \mathrm{C}$, showing aluminium adhesion (dark) on tool steel (light grey); sliding direction is horizontal to the shown image. b) 400x detail of the track.

At the temperatures of $350^{\circ} \mathrm{C}$ (not shown) and $450^{\circ} \mathrm{C}$ (Fig. 3 a), wear tracks show signs of abrasion Even though wear tracks present grooves similar in depth to those obtained at lower temperatures $(3 \mu \mathrm{m})$, adhesion lumps appear abraded or fragmented into smaller features (Fig. 3 b), and the resulting wear debris has been transported to the edges of the wear track. This mechanism is especially clear at $450{ }^{\circ} \mathrm{C}$. Additionally, even though ball hardness should be lower at these temperatures, wear tracks are narrower than at $30-250{ }^{\circ} \mathrm{C}$, indicating lower ball wear. It is possible that, at this range of temperatures, the formation of aluminium oxides is limiting material transfer and promoting abrasive wear mechanisms on the tool steel surface.
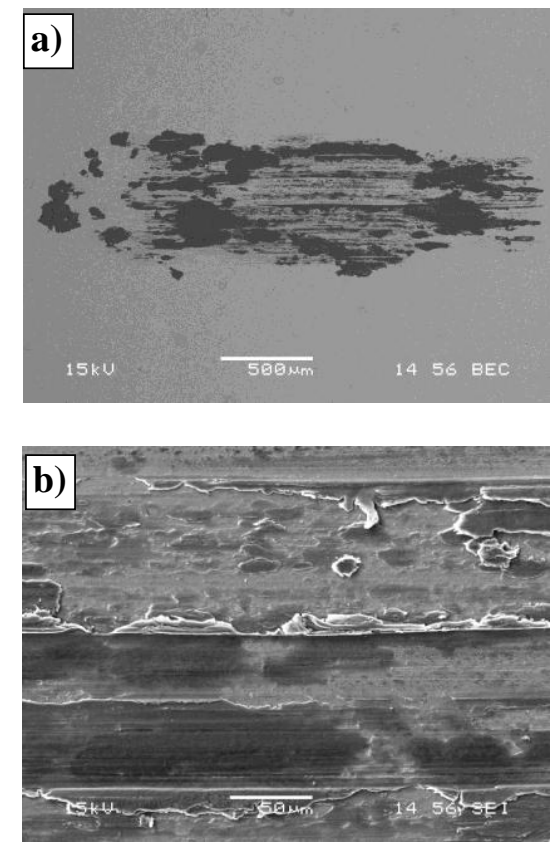

Figure 3: a) SEM/BSE overview of a wear track generated after $10 \mathrm{~s}$ of sliding at $450^{\circ} \mathrm{C}$; sliding direction is horizontal to the shown image. b) $400 x$ detail of the wear track, showing removal of aluminium adhesion lumps (dark) through abrasion.

\subsection{Effect of temperature in $300 \mathrm{~s}$ tests}

The main results obtained from the $300 \mathrm{~s}$ tests are summarised in Fig. 4, presenting the approximate ball wear calculated as indicated in section 2.3 , and in Fig. 5, showing examples of wear tracks (SEM/BSE overview and confocal microscopy topography) and measured coefficient of friction along the test for each temperature level. Different friction behaviour and wear track morphologies can be identified depending on the test temperature.

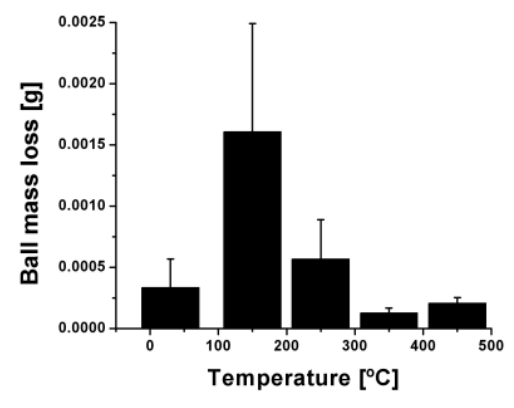

Figure 4: Ball wear at different temperatures in 300s tests, calculated as described in section 2.3. 

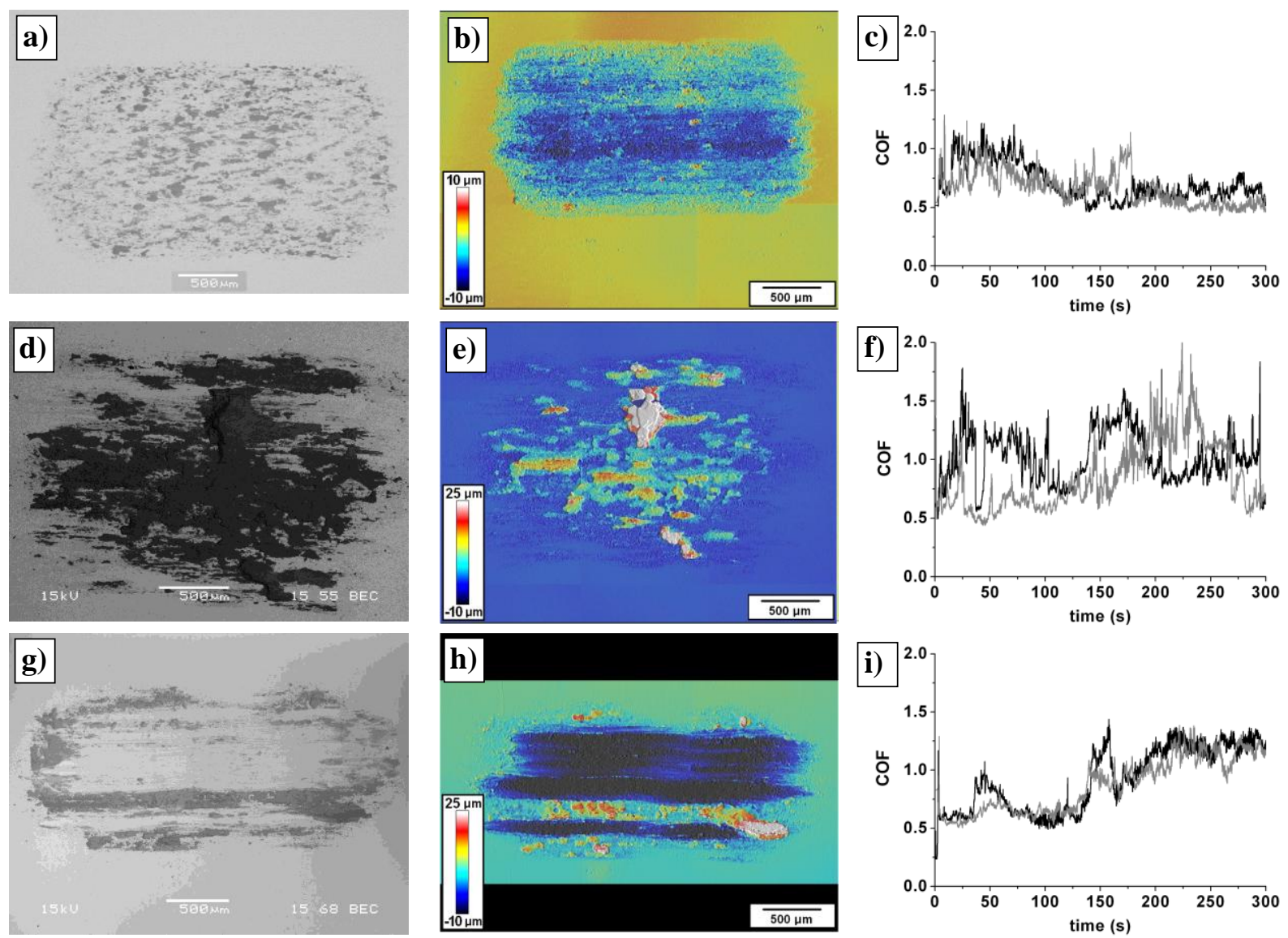

Figure 5: Images of selected wear tracks and corresponding coefficient of friction measurement generated by sliding AA2017 on polished 1.2344samples for 300 s at different temperatures. Left column: SEM/BSE 40x wear track overview. Centre column: Confocal microscopy topography. Right column: Coefficient of friction (two replicas of each test. a), b) and c) Room temperature, d), e) and f) $150^{\circ} \mathrm{C}, \mathrm{g}$ ), h) and i) $350{ }^{\circ} \mathrm{C}$. Sliding direction is horizontal to the shown images.

In tests run at room temperature, mainly abrasive wear appeared and a large amount of loose wear debris was generated. Wear tracks consisted of abrasion grooves of up to $10 \mu \mathrm{m}$ in depth, where small lumps of compacted aluminium debris were found (Fig. 6). No gross material transfer was observed and any lumps generated in the first $10 \mathrm{~s}$ of the test had been abraded. Coefficient of friction stabilized after approximately $100 \mathrm{~s}$, and showed good repeatability (Fig. 5 c).

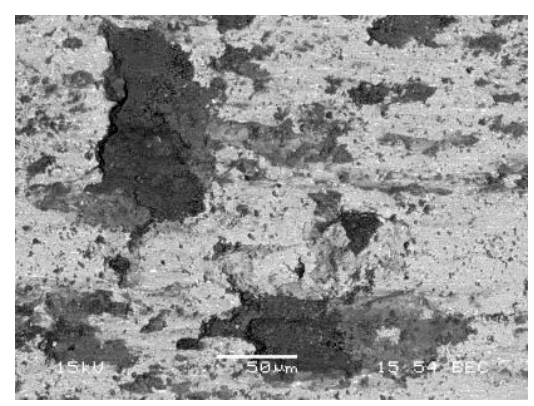

Figure 6: SEM/BSE 400x detail from wear track obtained after 300 s of sliding at room temperature.
These results indicate that most of the wear debris stays in the form of free-moving particles, acting as a third body abrasive element and lowering the coefficient of friction by limiting metal on metal interaction, as has been discussed by other authors [8].

At the temperatures of $150{ }^{\circ} \mathrm{C}$ (Fig. 5 d) and $250{ }^{\circ} \mathrm{C}$ (not shown) samples showed mainly aluminium transfer. The deepest wear grooves were less than $4 \mu \mathrm{m}$ in depth, similar to $10 \mathrm{~s}$ tests, indicating that abrasive wear was minimal beyond the initial sliding cycles. Unlike room temperature tests, lumps generated in the first $10 \mathrm{~s}$ of testing were not removed; instead, they acted as a nucleation site for further material transfer. This process took place during the whole $300 \mathrm{~s}$ of testing, as evidenced by the high, irregular COF measurements (Fig. 5 f), and happened through various mechanisms. The most important were aluminium transfer from the ball directly to the lumps on the surface through mechanical interaction and compaction of loose aluminium debris on existing surface features (Fig. 7). Through these mechanisms, 
observed by other authors in similar tribo-systems [6, $7,9]$ and mainly related to ball thermal softening and increased adhesion forces, existing lumps grew and new ones were generated. This behaviour generates high ball wear and high scatter in ball wear measurements (Fig. 4), especially in $150{ }^{\circ} \mathrm{C}$ tests where maximum material transfer occurs.

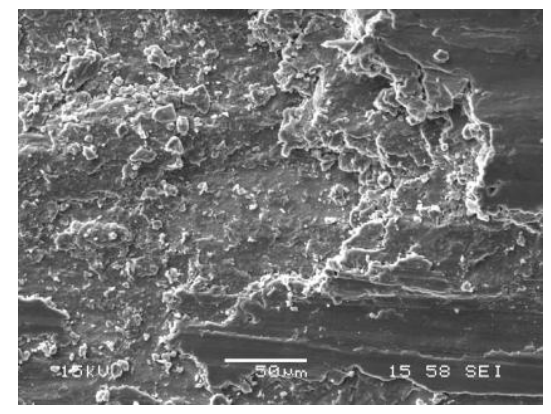

Figure 7: SEM 400x detail of a wear track obtained after $300 \mathrm{~s}$ of sliding at $150^{\circ} \mathrm{C}$, showing the compaction of wear debris onto previously existing lumps.

At $350{ }^{\circ} \mathrm{C}$ (Fig. 5 g) and $450{ }^{\circ} \mathrm{C}$, severe abrasion appeared. Wear grooves of up to $20 \mu \mathrm{m}$ were observed, generated by the abrasive action of the aluminium oxides. This caused the removal of previously adhered material and a noticeable loss of material from the tool steel sample. Material adhered on the disc consisted in the accumulation of wear debris transported by the ball and deposited outside the wear track (Fig. 8). On the other hand, ball wear scars were regular and ball mass loss much lower than in 150 and $250{ }^{\circ} \mathrm{C}$ tests. In some cases, a small volume of compacted wear debris could be observed attached to the ball wear scar. It must be noted that the protruding (red) band in Fig. $\mathbf{5} \mathbf{~ h}$ corresponds to a zone with little tribological interaction, as a large volume of material had been sheared from the corresponding ball region.

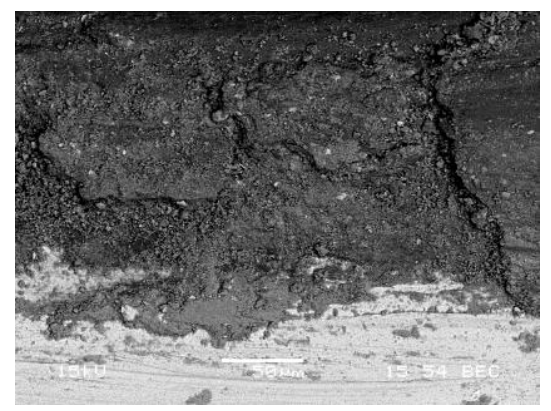

Figure 8: SEM/BSE 400x detail of a wear track corresponding to $300 \mathrm{~s}$ of sliding at $450^{\circ} \mathrm{C}$, showing the accumulation of loose wear debris (dark particles) on the border of a wear groove, eventually compacted into lumps.

All of this suggests that a protective layer of compacted oxides forms in the interface between the ball and the disk, a mechanism discussed by other authors for high temperature sliding of aluminium against steel [8]. Tests run at 350 and $450{ }^{\circ} \mathrm{C}$ show the highest repeatability, both in ball wear (Fig. 4) and COF (Fig. 5 i), as these layers limit ball wear and cause stabilization in the Coefficient of Friction

\subsection{Effect of surface finish}

In order to observe the effect of different roughness, texture and lay on the wear micro-mechanisms, tests using 1.2344 samples with different surface finishes were run for $10 \mathrm{~s}$ at $150{ }^{\circ} \mathrm{C}$, as results in section 3.2 showed material transfer to be maximum at this temperature. Fig. 9 shows SEM/BSE detail images from the studied samples; these images can be compared to Fig. $\mathbf{2}$ b, showing a detail of aluminium adhesion on a polished sample at $150{ }^{\circ} \mathrm{C}$.

On samples with lay perpendicular to the sliding direction (Fig. 9 a), aluminium adhered preferentially to the surface peaks, through a process of mechanical ploughing. This adhered material may serve as a nucleation point for further material transfer.

If surface lay is parallel to the sliding direction (Fig. $\mathbf{9} \mathbf{b}$ ), the ploughing effect of asperities is minimised, and material does not adhere to the surface peaks. In this case, aluminium wear debris appears mainly in the form of free moving particles, which become entrapped inside the surface grooves. If particles are small enough, they can move through grooves out of the contact. However, debris accumulated inside grooves can also be compacted into agglomerates by interaction with the aluminium ball; similar phenomena were observed by Pelcastre et al [9] when studying the effect of roughness in hot stamping of aluminium-silicon coated boron steel.

Lastly, samples with random texture (Fig. 9 c) showed a combination of the two mechanisms, with material accumulating inside grooves and sticking mechanically on the borders of the grooves with higher angle from the sliding direction.

On the other hand, gross material transfer was observed in all the studied samples, regardless of roughness and lay. Lumps more than $20 \mu \mathrm{m}$ high formed by adhesion and shearing of aluminium on the tool steel surface, as seen in section 3.1 with polished tool steel samples. For this reason, the overall influence of surface finish on wear behaviour was minimal. However, it is worth noting that the contribution of roughness-related phenomena to wear behaviour would probably be more relevant on samples with higher roughness and, therefore, wider peaks and grooves, as seen in the works of Heinrichs [4] and Pelcastre [9]. 

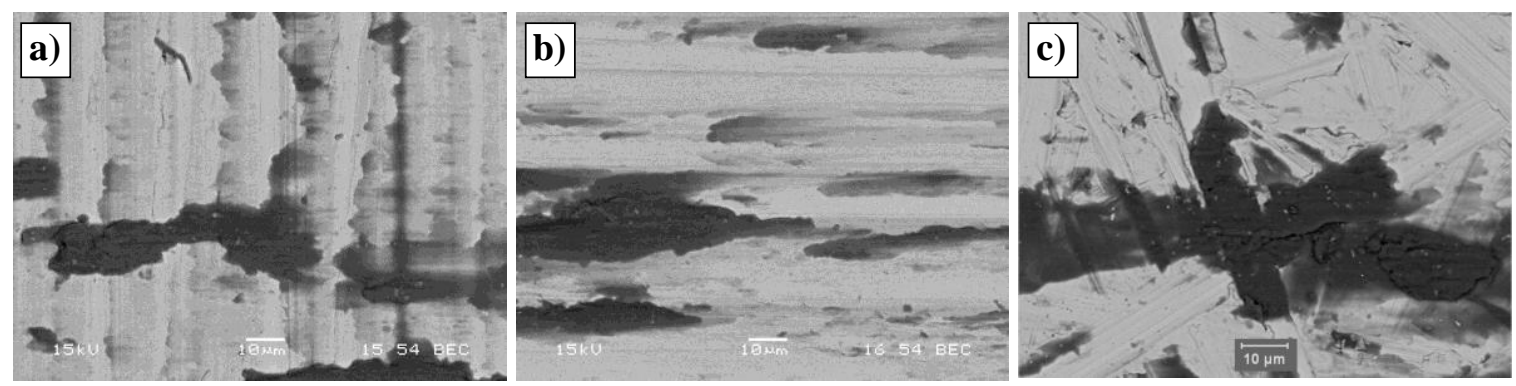

Figure 9: 1000x SEM/BSE images depicting the micromechanisms of material transfer on samples with different surface finish. a) Lay perpendicular to sliding direction. b) Lay parallel to sliding direction. c) Surface with random texture.

\section{CONCLUSIONS}

- System temperature plays a very important role in the wear behaviour of the aluminium-tool steel pair.

- Room temperature sliding generates moderate abrasive wear on both aluminium and tool steel. Material transfer is minimal and any aluminium previously adhered on the steel surface is abraded away. COF is low and stable, and tests show good repeatability.

- At temperatures from 150 to $250{ }^{\circ} \mathrm{C}$, material transfer mechanisms are the most active. Aluminium adheres on the tool steel through a variety of means, generating complex wear tracks and high, irregular COF. Mass loss of the aluminium counterpart is maximal in this temperature range.

- At temperatures higher than $350{ }^{\circ} \mathrm{C}$, semi-stable oxide compacts develop which limits galling. However, these oxides also generate severe abrasive wear on the tool steel surface.

- Tool surface finish does not affect the adhesion of aluminium lumps through chemical/metallurgical means; but it does generate additional material transfer through mainly mechanical micromechanisms. However, roughness of the samples studied in this work $(0.4 \mu \mathrm{m})$ was too low to significantly contribute to overall aluminium adhesion.

\section{REFERENCES}

1. W.S. Miller, L. Zhuang, J. Bottema, A.J. Wittebrood, P. De Smet, A. Haszler, A. Vieregge. Recent development in aluminium alloys for the automotive industry. Materials Science and Engineering A 280(2000), 37-49
2. Hanna M D. Tribological evaluation of aluminium and magnesium sheet forming at high temperatures. Wear 267(2009) 1046-1050.

3. P. Groche, G. Nitzsche. Influence of temperature on the initiation of adhesive wear with respect to deep drawing of aluminium-alloys. Journal of Materials Processing Technology 191(2007) 314-316

4. J. Heinrichs, S. Jacobson. The influence from shape and size of tool surface defects on the occurrence of galling in cold forming of aluminium. Wear 271(2011) 2517-2524

5. M. Pellizzari. High temperature wear and friction behaviour of nitrided, PVD-duplex and CVD coated tool steel against $6082 \mathrm{Al}$ alloy. Wear 271(2011), 2089-2099.

6. L. Wang, Y. He, J. Zhou, J. Duszczyk. Effect of temperature on the frictional behaviour of an aluminium alloy sliding against steel during ballon-disc tests. Tribology Interational 43(2010), 299-306.

7. M. Vilaseca, S. Molas, D. Casellas. High Temperature Tribological Behaviour of Tool Steels During Sliding against Aluminium. Wear 272(2001) 105-109

8. J. Jiang, F.H. Stott, M.M. Stack. A generic model for dry sliding wear of metals at elevated temperatures. Wear 256(2004) 973-985.

9. L. Pelcastre, J. Hardell, B. Prakash. Investigations into the occurrence of galling during hot forming of Al-Si coated high strength steel. Proceedings of the Institutions of Mechanical Engineers, Part J: Journal of Engineering Tribology 255(2011) 487-498

\section{ACKNOWLEDGEMENTS}

Authors from Fundació CTM Centre Tecnològic acknowledge the Catalan government for partially funding this work under grant TECCTA11-1-0006. 